\title{
Rules, Social Ontology and Collective Identity
}

\section{NUNO MARTINS}

\section{INTRODUCTION}

In non-cooperative game theory - and also in microeconomic theory in generalsocial behaviour is explained under the assumption that human action is permanently driven by the pursuit of individual goals, which Amartya Sen (2002) calls the agent's "self-goals". Sen criticises this approach, and argues that the explanation of social behaviour should take into account that human agents are: capable of seeing themselves as part of a "community" (with which they share a common "identity"); and capable of following rules of behaviour towards members of this community that may be out of phase with their own (individual) "self-goals".

Throughout this paper I argue that Sen's critique of game theory (and of mainstream economic theory in general) can be fruitfully linked to John Searle's (1995) notion of collective intentionality, and also to the critical realist transformational model of social activity, as developed by such authors as Margaret Archer (1995, 2000), Roy Bhaskar $(1975,1989)$ and Tony Lawson $(1997,2003)$, amongst others. I suggest that a conception where social rules are ontologically irreducible to (albeit emergent from) human agency, in line with the critical realist transformational model of social activity, can solve some possible inconsistencies in Sen's approach.

Section 2 of the paper scrutinises the nature of Sen's contribution. Section 3 examines Sen's critique of game theory. In section 4 I argue that Searle's notion of collective intentionality can be fruitfully linked to Sen's critique, and Sen's idea of "collective" identity. In section 5 I will identify a possible tension in Sen's conception of social behaviour, and in section $6 \mathrm{I}$ will suggest the critical realist transformational model of social activity as a solution to such tension. In section 7 I will examine the causal role of social structures, and in section 8 I will discuss the underlying capacities and dispositions of the human agent. Some concluding remarks will be made in section 9 .

\section{THE NATURE OF SEN'S CONTRIBUTION}

In order to understand Sen's critique of mainstream game theory, one must note that he does not provide a complete theory of social behaviour. In fact, Sen does 
not so much provide an alternative theory, as the conceptual tools for a theory of social behaviour to be developed, by scrutinising the nature of social and economic behaviour at a more general level. In so doing, Sen engages (albeit without explicitly acknowledging it) in what may be termed as an exercise in social ontology.

By ontology I mean an enquiry to the nature of reality. Hence, social ontology is concerned with social being, and investigates the entities that exist in social reality and their properties. Social being refers to the part of reality that depends at least in part upon human beings - see Lawson (1997, 2003). The purpose of an ontological investigation is to understand categories based upon which social science can proceed, but not necessarily to develop a substantive social theory using such categories. Although ontological categories are of course used in social sciences, there is a difference between clarifying what they mean, and using them to construct a specific social theory.

The study of the ontological presuppositions of scientific research, or of social activity in general, is based on what Lawson calls the intelligibility principle, according to which "all actual practices, whether or not scientific, and whether or not successful on their own terms, have explanations" (Lawson 2003: 33). Of course, as Lawson (2003: 33/34) also notes, any ontological analysis of the conditions of possibility of human practices will be conditional on the premises chosen, that is, on the practices which we select in order to initiate such ontological study.

Now, ontology can be undertaken at different levels of abstraction: either in order to understand which entities constitute social being; or, at a more abstract level, in order to clarify the general properties of those entities and of social reality. Explicitly ontological contributions often work at a higher level of abstraction, describing not only social entities, but also the more general properties of those entities and of the social realm - properties such as "causality" or "interconnectivity", for example. Authors like Margaret Archer (1995, 2000), Roy Bhaskar (1975, 1989), Tony Lawson (1997, 2003), and John Searle (1995), have explicitly developed a social ontology, concerned with scrutinising the more general properties of the social realm.

Unlike Archer, Bhaskar, Lawson and Searle, Sen does not explicitly elaborate the more general properties of the social realm. Sen's critique of game theory leads him to engage in an ontological description of human behaviour at a general level, taking into account the role of social rules and identity in such behaviour - and an analysis of Sen's overall contribution would show that he also engages in the ontological analysis of social entities like functionings, capabilities or well-being - see Martins (2006, 2007b).

Sen's criticism of modern economic theory, and of game theory, has been paralleled by his suggestion that economics can benefit greatly from a closer contact with ethics. Hilary Putnam (2002) and Vivian Walsh (2000, 2003) consider this return to an integrated view of ethics and economics to be the 
essence of the "Senian" project, a project in which economics recovers the rich philosophical anthropology that constitutes part of the legacy of Adam Smith.

Now, one could argue that the main emphasis of Sen's work on social behaviour has been on the ethical dimension of human behaviour, rather than on the ontological aspects of the latter. However, such a claim presupposes a clear distinction between ethics and ontology, and ethics and ontology cannot be separated in Sen's contribution - for elaborations, see Martins (2007a). It is true that a complete understanding of Sen's analysis of social structures and rule-following behaviour cannot disregard the prescriptive dimension of social rules. Sen has consistently argued for the importance of incorporating prescriptive ethical motivations, such as moral imperatives, in economic analysis.

Nevertheless, one must distinguish between a conception of ethics where ontology (supposedly) plays no role, and ethics would be exclusively concerned with prescriptive criteria for decision-making, and an integrated view of ethics and ontology, where ethical evaluation is much concerned with the description of the space to which prescriptive criteria are to be applied (such as the space of capabilities or functionings), or with categories like "social rules", "identity", "commitment", and the like, and their impact on behaviour, from an ontological point of view.

Adam Smith's (2002 [1759]) Theory of Moral Sentiments is an example of an ethical treatise with an integrated view of ethical prescription and ontological description, that underpins Smith's analysis of concepts like "sympathy" and "prudence" which is at many stages essentially descriptive (aimed at understanding what these concepts mean, not at obtaining prescriptive criteria or moral imperatives). Another example of an integrated perspective of ethics and ontology can be found in the writings of Aristotle, where the emphasis is on the description of virtuous habits and dispositions.

In a similar vein to Adam Smith and Aristotle - who Sen (1999) recognises as key influences of his own writings - Sen's work on ethics has been more concerned with ontological description, by elaborating such categories as "social rules", "identity", "commitment", "capabilities", "functionings", "well-being", and the like, from an ontological point of view, and not with prescriptive ethical criteria only. If bringing ethics into economics means not only to make prescriptive judgments, but also to engage in an ontological description of spaces like capabilities or functionings, or of social norms of conduct, then Sen's project is clearly permeated by an ontological dimension. When Sen speaks of ethics, it is this Smithian and Aristotelian approach to ethics (concerned not only with prescription, but especially with ontological description) that Sen has in mind. ${ }^{1}$

Sen's suggestion of a greater contact between ethics and economics opens a wide variety of possible avenues of research in economic analysis. But in order to understand the characteristics of social behaviour that Sen discusses, it is necessary to elaborate more on their ontological conditions of possibility. Whilst Sen's contribution can be interpreted as an exercise in ontological description 
(and not just in ethical prescription), he does not engage in the (more abstract) ontological analysis of the properties of the social realm.

I will argue that the social ontology of Searle, and also the contributions of critical realism, can be very useful for elaborating and clarifying Sen's conception of social reality at a more general level, that is, at the level of the properties which underpin the ontological entities that Sen describes. I will present now Sen's critique of mainstream game theory, and afterwards clarify Sen's conception of social behaviour by focusing on an ontological dimension of Sen's work that has been relatively neglected in the literature.

\section{GAME THEORY, SOGIAL BEHAVIOUR AND COLLECTIVE IDENTITY}

In traditional game theory analysis, human behaviour is explicated under the assumption that human action is permanently driven by the pursuit of individual goals. It is assumed that agents know which strategy maximises their individual payoffs, and invariably follow such a strategy. Sen $(1987,2002)$ provides a critique of this explanation of human behaviour. Sen (2002) notes that the self-interested behavioural structure of the human agent that underpins mainstream (micro)economic theory (including mainstream game theory) posits what he describes as the three features of the self: "self-centred welfare", "self-welfare goal" and "self-goal choice". "Self-centred welfare" means that the individual's welfare is not affected by the welfare of other agents; "self-welfare goal" means that the individual has no goal other than her or his welfare (even though the latter may be affected by the welfare of other agents, or not); and "self-goal choice" signifies that all the individual's choices are made in accordance with her or his goals (regardless of how the latter are defined).

A much debated issue in game theory is how social cooperation can arise when: (a) it is always advantageous for each individual not to cooperate (regardless of whether other individuals cooperate or not); and (b) all individuals would be better off if all would cooperate, rather than if there were no cooperation. One example often discussed in this context is the "prisoner's dilemma" situation, where in a "one-shot" game it is always better for a player not to cooperate (both in the case where the other player cooperates and in the case where (s)he does not, and so "not cooperating" is a dominant strategy, that is, it is preferred regardless of what other players do), but if both players would cooperate, both would achieve a higher level of welfare. ${ }^{2}$

The dominance of non-cooperative strategies in the prisoner's dilemma springs from the fact that agents are supposed to pursue their "self-goals" only, and can happen even in the absence of "self-centred welfare" and "self-welfare goal". For example, agents with altruistic concerns (which need not include any concerns with their own welfare, and need not be self-centred as well, but would be individual goals nevertheless) might still, for some reason, have these "altruistic" 
goals ranked in the same way as payoffs are usually ranked in the prisoner's dilemma. Hence, even without "self-centred welfare" and "self-welfare goal", the existence of "self-goal choice" would be a sufficient condition for the emergence of a prisoner's dilemma situation-see also Derek Parfit $(1981,1984)$.

In fact, even when "self-goals" include not only the agents' welfare, but also any other type of individual goals (such as a concern with the welfare of other agents), those "self-goals" would be still individual goals (regardless of how broadly defined), and Sen's point is that social behaviour is irreducible to individualistic "self-goal" pursuit. Sen argues that the key to resolve the prisoner's dilemma is to think "in terms of social strategy" (Sen 1987: 86), instead of trying to derive these social aspects from individualistic interplay:

\begin{abstract}
"Behaviour is ultimately a social matter as well, and thinking in terms of what 'we' should do, or what should be 'our' strategy, may reflect a sense of identity involving recognition of other people's goals and the mutual interdependencies involved. [...] The language of game theory - and indeed of economic theory - makes it hard to discuss behaviour patterns of this kind, since it is very tempting to think that whatever a person may appear to be maximizing, on a simple interpretation, must be that person's goal." (Sen 1987: 85)
\end{abstract}

Sen suggests starting from the social notion of the "identity" of a community, instead of trying to explain social behaviour in terms of the individual interaction of self-goal pursuing agents:

\footnotetext{
"The rejection of self-goal choice reflects a type of commitment that is not able to be captured by the broadening of the goals to be pursued. It calls for behavior norms that depart from the pursuit of goals in certain systematic ways. Such norms can be analyzed in terms of a sense of 'identity' generated in a community (without leading to a congruence of goals), and it has close links with the case for rule-based conduct, discussed by Adam Smith. [...] It is an alternative program to the recent attempts at 'resolving' the [prisoner's] dilemma through the relaxation of the assumption of mutual knowledge in finitely repeated games." (Sen 2002: 219/220)
}

It is important to note that the target of Sen's criticism is only traditional game theory, where it is presupposed that agents permanently engage in the pursuit of their self-goals. Sen offers no criticism of approaches to game theory which do not presuppose permanent self-goal pursuit, such as evolutionary game theory approaches where conventions are the key element to explanation.

In fact, Sen (1997) supports evolutionary game theory, arguing that it can provide important insights to the study of behavioural norms and rule-based conduct. Furthermore, authors studying conventions from a game theory perspective often adopt a conception of "we-rationality" which is very close to Sen's (1987) notion of "social strategy" — see, for example, Sugden (2000), or Hollis and Sugden (1993).

Nevertheless, notions like "rule-based conduct" and "sense of identity" with a community require further analysis. What are the conditions of possibility for this type of social behaviour? And what does it mean to identify with others? I will try to clarify these points in the next sections. 
Sen's conception of collective identity can be fruitfully linked to John Searle's notion of collective intentionality, which means to "share intentional states such as beliefs, desires, and intentions" (Searle 1995: 23). Searle argues that the collective intentionality of a community is irreducible to the singular intentionality of individual agents:

\begin{abstract}
"What is the relation between singular and collective intentionality, between, for example, the facts described by 'I intend' and 'We intend'? Most efforts I have seen to answer this question try to reduce 'We intentionality' to 'I intentionality' plus something else, usually mutual beliefs. The idea is that if we intend to do something together, then that consists in the fact that I intend to do it in the belief that you also intend to do it; and you intend to do it in the belief that I also intend to do it. And each believes that the other has these beliefs, and has these beliefs about these beliefs ... etc., in a potentially infinite hierarchy of beliefs. 'I believe that you believe that I believe that you believe that I believe ....', and so on. In my view, all these efforts to reduce collective intentionality to individual intentionality fail. Collective intentionality is a biologically primitive phenomenon that cannot be reduced to or eliminated in favor of something else." (Searle 1995: 24)
\end{abstract}

Searle concludes that:

\begin{abstract}
"The crucial element in collective intentionality is a sense of doing (wanting, believing, etc.) something together, and the individual intentionality that each person has is derived from the collective intentionality that they share." (Searle 1995: 24/25, emphasis in original)
\end{abstract}

Searle uses the expression "social fact" to refer to "any fact involving collective intentionality" (Searle 1995: 26). Collective intentionality is a condition of possibility for us to follow social rules of behaviour. Whenever we occupy a given social position (such as being citizen of a country, member of a family or teacher at a university), there will be a set of rules we are expected to follow and, likewise, a set of rules we expect people in other social positions to follow towards us.

But whenever following rules, people who occupy different positions in a network of interrelated social positions will all be engaging in a form of collective behaviour, in which they share intentions, beliefs and desires. For example, if a person $\mathrm{X}$ follows a given rule of behaviour when relating to person $\mathrm{Y}$ (for example, when person $\mathrm{X}$ pays a good bought at person Y's store), both $\mathrm{X}$ and $\mathrm{Y}$ (who occupy the social position of buyer and seller, respectively) are engaging in a form of collective behaviour (in this case, commercial exchange) which requires shared intentionality.

Collective intentionality can be seen as a condition of possibility of Sen's notion of "identity" of a community. Identifying ourselves with a community means to recognise ourselves as part of a social structure, and place ourselves in a given social position within an interrelated network of social positions (each associated with a set of social rules), through which we are connected to the other members 
of the community. Sen's idea of acting in terms of our strategy, as opposed to permanently engaging in individualistic self-goal pursuit, presupposes Searle's notion of doing something together (sharing beliefs, desires and intentions when acting in accordance with the rules of behaviour that are attached to each social position in a given social structure), following a social strategy - as opposed to an individual strategy.

Hence, collective intentionality enables the emergence of a "collective" identity, which in turn provides the basis for the formation of social structures - following Lawson (2003), social structures can in turn be seen as constituted by an interrelated network of social positions, with each position attached to given social rules, but this is a topic to address later.

Now, in dynamic game theory - for example Kreps and Wilson (1982) - many explanations for social cooperation have been provided where the agents' beliefs and expectations are also taken into account. Since these beliefs and expectations are conditional upon the observed social practices and corresponding rules, one could ask whether in dynamic game theory much of the points just made concerning beliefs about social rules are already accounted for.

However, the usual procedure in dynamic game theory is still to derive social cooperation from the atomistic interaction of "self-goal" pursuing agents. It is true that much game theory analysis resorts to the notion of beliefs. ${ }^{3}$ But this is done in order to derive social behaviour from individual intentionality plus individual beliefs. If the beliefs of human agents are taken to be individual beliefs about the other individual's own beliefs, we still have a case of individual intentionality, not a case where common beliefs are shared by different individuals. On Searle's (1995: 25) approach, on the other hand, both beliefs and individual intentionality are explained through the notion of collective intentionality.

\section{SOCIAL RULES AND HUMAN AGENCY}

There are, nevertheless, some other problematic issues that are commonly associated with Searle's notion of collective intentionality. Collective intentionality is often reduced to individual intentionality under the conviction that doing so is the only way to preserve the autonomy of the human agent. Searle notes that:

\footnotetext{
"[ . . . it has seemed that anybody who recognizes collective intentionality as a primitive form of mental life must be committed to the idea that there exists some Hegelian world spirit, a collective consciousness, or something equally implausible. The requirements of methodological individualism seem to force us to reduce collective intentionality to individual intentionality." (Searle 1995: 25)
}

If collective intentionality meant a collective consciousness that somehow would determine human action, it would ultimately preclude the autonomy of the human agent. Sen's own terms already create a similar tension between social 
structures and human agency, since Sen argues that social rules must be "taken for granted" by agents when interacting:

\begin{abstract}
"If the sense of identity takes the form of partly disconnecting a person's choice of actions from the pursuit of self-goal, then a non-inferior outcome can well emerge even without any formal contract or enforcement. One of the ways in which the sense of identity can operate is through making members of a community accept certain rules as part of obligatory behavior toward others in the community. It is not a matter of asking at each time, What do I get out of it? How are my goals furthered in this way?, but of taking for granted the case for certain patterns of behavior toward others.

In fact, acceptance of rules of conduct toward others with whom one has some sense of identity is part of a more general behavioral phenomenon of acting according to fixed rules, without following the dictates of goal maximization. Adam Smith had emphasized the importance of such 'rules of conduct' in social achievement: 'Those general rules of conduct, when they have been fixed in our mind by habitual reflection, are of great use in correcting misrepresentations of self-love concerning what is fit and proper to be done in our particular situation' ([1790]: 160)" (Sen 2002: 216/217).
\end{abstract}

So, for Sen, "rule-based conduct" is a phenomenon that cannot be entirely derived from the interaction of "self-goal" pursuing agents (as in traditional game theory) because, for one thing, (fixed) rules of conduct are already pre-existent (and taken for granted) at each moment when individuals act.

But Sen's claim that "fixed rules" of conduct must be "taken for granted" when engaging in social behaviour, for example, could seem to suggest a deterministic view where social "rules of conduct" are reified and human agency is entirely determined by ("fixed") social rules. It could seem that we have criticised a conception where collective intentionality and social rules of conduct are reduced to individual intentionality, to move towards a diametrically opposite conception where human action is completely determined by social rules, or the social structure of which these social rules are a constitutive part, or some collective consciousness.

In earlier writings, Sen addresses the topic of determinism, and defends a form of historical determinism from several criticisms, trying to allow for a conception where an action can be causally determined, but nevertheless agents are free in the sense that they are following values and preferences:

\footnotetext{
"Let there be three alternative policies, A, B and C, open to a given set of men leading respectively to results $\mathrm{A}^{\prime}, \mathrm{B}^{\prime}$ and $\mathrm{C}^{\prime}$. They like, let us say, $\mathrm{B}^{\prime}$ best of all and, therefore, choose to do B. There was no external compulsion for them to choose B, but they do so because they prefer $\mathrm{B}^{\prime}$. Thus, in a certain sense (and that is the only sense that matters to the people involved), they are free to choose and B is the result of their free choice. There is, therefore, no reason for them to be fatalists. On the other hand, in so far as their values, preferences, impulses and the reaction system determining the choice are products of their inherited and acquired nature, their choice is determined by the past. Given the causal relations, one would have to be able to predict what they would have chosen, even though in the only sense that is relevant to them as decision-makers, they were free to choose what they liked" (Sen 1959: 111)
} 
Here Sen is arguing for the causal efficacy of past conditions (including social factors like values, amongst others), suggesting a deterministic view of the causal relation in the social realm, while trying to preserve a notion of human freedom where the latter consists in following values, preferences and impulses, amongst other factors.

However, is it sufficient for Sen's conception of freedom to see it as the ability to engage in choices which are determined by values, preferences and other social or natural conditions, as Sen does in this earlier writing? Or, looking at Sen's latter writings, is it sufficient for Sen's account of social behaviour that the latter consists in permanently obeying to fixed rules, which are followed by the group we identify with?

More recently, Sen (2006) also argues that human agents have a plurality of identities, and that there is no need to see one of these identities as the sole determinant of human action, which seems to suggest that human agents are able to scrutinise, reflect upon, and be critical of, the social rules and norms which characterise a given group that we may identify ourselves with. This idea is in line with Sen's (2002) conception of rationality:

\footnotetext{
"Rationality is interpreted here, broadly, as the discipline of subjecting one's choices - of actions as well as of objectives, values and priorities - to reasoned scrutiny. Rather than defining rationality in terms of some formulaic conditions that have been proposed in the literature (such as satisfying some prespecified axioms of 'internal consistency of choice', or being in conformity with 'intelligent pursuit of self-interest', or being some variant of maximizing behavior), rationality is seen here in much more general terms as the need to subject one's choices to the demands of reason." (Sen 2002: 4)
}

So the account of rationality that Sen defends is one where rationality does not consist in following one preference ordering, set of values, fixed rules, or identity, but rather to have the capacity of reflecting upon preferences, values, rules, and identity, and possibly changing them. So to see human action as totally determined by underlying social rules, structures, identities, or collective consciousness, would be inconsistent with Sen's (1987, 1997, 2002) own conception of agency and rationality, and with Sen's (2006) more recent writings on identity. Autonomy and freedom of choice are essential to human agency in Sen's thinking.

Furthermore, Sen (1997) also argues that preference orderings can be irreducibly incomplete, in the sense that it may not be possible to rank two options A and B in any way, which means that in such cases it will be impossible to predict human choice.

There is thus a tension in Sen's work, which is also present in later writings, concerning the way in which human action is caused (including the causal role of social structures, "fixed rules" and identity), and human freedom. Sen does not clarify how it can be the case that human agents take for granted fixed rules (or have their actions in some way causally determined by past conditions), and 
nevertheless have the capacity of changing these rules. If human agents have the capacity of changing rules, we fail to see in what sense rules are simply to be taken for granted.

To be consistent with Sen's analysis, one must allow for the existence of social rules as irreducible to human agency (so that social rules can be "taken for granted"), but human agency must not be seen as entirely determined by social rules - so that freedom of choice exists, and Sen's conception of rationality and agency can be maintained. The problem is that once we assume that the causal relation must be unidirectional (either social rules, or values, determine human agency, or social rules are reducible to the atomistic interaction of human agents), our solution to this problem will consist in reducing one of these concepts (social rules or human agency) to the other. The key to this imbroglio must be a conception where neither social rules nor human agency can be reduced to something else, or to each other.

I will now argue that in order to make Sen's conception of collective identity coherent with his writings on agency and rationality, Sen's notion of identity must be seen under the light of a social ontology perspective in which both social rules of behaviour and human agency are ontologically real, and ontologically distinct from (and irreducible to, albeit dependent upon) each other. I will draw upon a series of contributions under the heading of critical realism - on which see Archer, Bhaskar, Collier, Lawson and Norrie (1998), Archer (1995, 2000), Bhaskar (1975, 1989), or Lawson $(1997,2003)$ - to explain the interaction between human agency and social rules.

I will argue that the critical realist transformational conception of social activity can be fruitfully combined with Sen's argument against non-cooperative game theory analysis. This ontological distinction will help us to explain why: (i) social rules are already pre-existent at each moment; and (ii) freedom of choice and reasoned scrutiny is not denied.

\section{THE TRANSFORMATIONAL MODEL OF SOCIAL ACTIVITY}

Like Sen, critical realists hold a view of social behaviour where the latter is irreducible to the atomistic interplay of "self-goal" pursuing agents. According to critical realism, social rules are part of an enduring (dynamic) social structure, drawn upon by human agents. This follows from the critical realist transformational model of social activity.

In the transformational model of social activity, social structures (comprising social rules) are not only the continuously reproduced and/or transformed unintended outcome of intentional human agency, but also the condition of possibility of individual agency. Based on the social structure, human agents build their expectations and beliefs about what can happen. Agents take into account that what other agents do is constrained or facilitated by this social structure, which 
provides an enduring reality that enables agents to engage in coordinated and cooperative behaviour.

Note, nevertheless, that to say social structures, including social rules, are pre-existent at each moment does not mean they do not depend upon human agency, from which they first emerged. For Lawson (1997: 63), "[e]mergence may be defined as a relationship between two features or aspects such that one arises out of the other and yet, while perhaps being capable of reacting back to it, remains causally and taxonomically irreducible to it". Social structures are not only the necessary condition of human action, but also the consequence of human intentional agency, from which the former emerge. As Lawson explains:

"[R]eproduction or transformation as occurs is the result of capable human beings purposefully going about their daily lives and tasks, interpreting themselves, their purposes and the social order in very definite ways, and continually interacting with (including copying) others." (Lawson 2003: 130)

But even though social structures emerge from human agency, both social structures and human agency are irreducible to each other. The reason why social structures and human agency are both irreducible to each other is because they are ontologically distinct. Remember that ontology is an enquiry to the nature of reality, which investigates the entities that exist, and their properties. So to say that both social structures and human agency are ontologically real and distinct entities means that: (a) both social structures and human agency are a constitutive part of social reality (of social being); and (b) even though social structures and human agency are interdependent, they are different modes of social being.

Rules of behaviour are attached to the social position to which human agents slot within a social structure, not to human agents themselves. Even if we assume, following Searle (1995), that human agents share intentional states whenever engaging in social behaviour, the social structure in which they are positioned would still be, according to the critical realist perspective, ontologically distinct from the human agent who slots into it, and from her or his own subjectivity.

Some social structures and communities will be more important in shaping the personality and identity of the individual than others (and different individuals will prioritise different social structures and communities to which they may belong in different ways). But whatever the importance that a given social structure or community has for our personality and identity, it still remains the case that our reasoning, subjectivity and reflexivity gives us the possibility of at least trying to choose and change our identities, affiliations and social positions - see Archer $(2000,2007)$ for a discussion.

The fact that it may be extremely difficult to choose and change our identities, affiliations and social positions, shows how social structures play an important role in facilitating or constraining human agency, but does not entail that there is no 
distinction between the social structures in which we are positioned on the one hand, and our own subjectivity and reflexivity on the other hand-for the mere possibility of choosing and changing our identities, affiliations and social positions, even if unrealised in practice, is sufficient for us to recognise the ontological distinction between social structures and human agency. It is because of this ontological distinction that social structures are not merely reproduced through human agency (as it would be in a conception where social structures would determine human agency), but also transformed.

Now, how does this transformational conception of social activity help us to understand Sen's notion of "collective" identity? Remember that, in Sen's view, one would have to allow for both: (i) the primacy of collective identity, in a conception where human agents take "for granted the case for certain patterns of behaviour toward others", while "acting according to fixed rules"; and (ii) that freedom of choice and freedom of scrutinising goals and values be a central component of social reality. Most mainstream economic theory models, where social rules of conduct are derived from atomistic self-goal pursuit, are inconsistent with claim (i) - in fact, this is the core of Sen's critique of traditional game theory. Models where social structures are reified (and determine behaviour) are certainly consistent with claim (i), but are incompatible with claim (ii).

The transformational model of social activity, on the other hand, is consistent with both claims (i) and (ii). In the transformational model of social activity, both social rules of conduct and freedom of choice can be real constituents of social reality (as they must be for Sen), in a conception where social structures (including social rules) and human agency are ontologically distinct (albeit interdependent) modes of being.

Hence, it seems that the transformational model of social activity provides us with an account that renders Sen's views on social behaviour and on agency (and rationality) coherent. Even though the social structure arises through the interaction of human agents, these agents take such structure (and the rules and positions it comprises) as given at each moment they act-just like in Sen's analysis "rules of conduct" are "taken for granted". So when human agents identify themselves with a community, they have the capacity to follow the rules of such community, but their actions are not determined by the social structures which characterise such community.

\section{ON THE CAUSAL ROLE OF SOCIAL STRUCTURES}

It is important to note that the causal role of social structures has been a subject of much controversy. While it is recognised by authors like Archer (1995, 2000, 2007) Bhaskar $(1975,1989)$ or Lawson $(1997,2003)$ that emergent social structures do have a causal role, the exact status of emergent structures constitutes a subject of much debate. 
Even in recent discussions, the causal efficacy of social structures still raises many doubts - on which see, for example, Elder-Vass (2007a, 2007b), King (2007), Porpora (2007) and Varela (2007) — much stimulated by the differences between the interpretation of the putative causal role of social structures in critical realism and in Harré's writings - see Harré and Bhaskar (2001) — and especially by Harré's criticism of the presupposition that social structures have a causal efficacy on their own.

Harré and Varela (1996) argue that only particular entities possess causal powers. An object is what Harré and Varela call a "powerful particular", that is, a causal agent, endowed with causal powers, in virtue of its intrinsic nature or structure. But for Harré and Varela, it is human agents, and not social structures, who possess causal powers and initiate an action. Thus, it is human agents, and not social structures, who are the powerful particulars in the social realm, and hence the attribution of causal efficacy to society is a mistake-for a criticism of Harré's position see also Kaidesoja (2007).

A possible solution to the debate concerning the causal role of social structures has been suggested by Paul Lewis (2000) who, following Bhaskar (1989), argues that the Aristotelian distinction between material causes and efficient causes could clarify this point. According to Bhaskar and Lewis, social structures could be seen as material causes which enable or constrain the types of action which can occur, while human agency is the efficient cause of an event. Thus, only human agents would be what Harré and Varela (1996) call "powerful particulars", since only they are the efficient cause that initiates an action. However, as critical realists argue, this action would be constrained or enabled by the material cause, namely social structures. This solution has been also suggested in the context of Sen's capability approach in Martins (2007b).

Manicas (2006: 72/73) argues that the solution Lewis suggests does not provide a clear analogy with the Aristotelian example, in which the marble is the material cause, while the sculptor is the efficient cause, of the production of a sculpture, for marble is "independent of persons and their actions and thus can have causal powers", while "social structure is concept- and activity-dependent and agencydependent". However, if we approach the idea using the notion of emergence the analogy is clear enough. The concept of a material cause can be seen as a way to conceptualise the idea that once a given entity arises of a lower level, it becomes a material with a set of emergent properties which have causal powers.

The marble emerges as a solid entity from a lower level of atoms and molecules. Its emergent properties, such as solidity, are permanently reproduced through the lower level activity of atomic and molecular phenomena, in the same way that emergent social structures are constantly reproduced through human practice guided by conceptions. We need neither see the marble as being dependent upon of the activity of human agents, or social structures as being independent from the activity of human agents, for the analogy to hold. Although human activity constitutes the lower level from which social structures emerge, it is not 
the lower level from which marble emerges. So for the analogy to hold, each emergent entity must be dependent upon the activity of the respective lower level from which it emerges: the activity of atomic and molecular phenomena in what the marble is concerned, human activity in what concerns social structures.

In other words, from the point of view of the production of the sculpture, the marble, as an emergent entity with all its emergent properties such as solidity, is used as a material through which the efficient causation of the labour of the sculptor will produce something. In the same way, social structures are an emergent material used by an agent, who is the efficient cause, to perform an action. The dependence upon a lower level activity for the maintenance of emergent properties is true both for the marble and for the social structures, but both emergent entities depend upon different lower levels.

Note that Sen (2002: 217) also says we act "acting according to fixed rules". This could suggest that rules are just what Aristotle calls a formal cause, for they provide the form of an action which we copy in a particular action. But must a rule be seen as an exact description of an action or practice? Lawson argues:

\footnotetext{
"any rule only carries normative or legitimising or facilitating (constitutive/regulative/moral/ semantic) force. A social rule, in other words, is a formulation of action that, under specified conditions, must, should, or can usefully, legitimately, meaningfully, or advisedly, etc., be carried out, rather than a prediction or observation of an action." (Lawson 2003: 37)
}

And he continues:

This suggests that actions need not conform to the form of the rule, which is often expressed as a norm or obligation or convention, and so the rule is only a material cause in the sense that it constrains or enables behaviour through its influence on human action.

In fact, the citation from Smith that Sen (2002: 217) chooses above, also suggests Lawson's interpretation of rules, for Smith notes how "general rules of conduct" which "have been fixed in our mind" help us to correct misrepresentations and guide us in choosing "what is fit and proper to be done in our particular situation". So although for Smith and Sen rules are fixed in our mind, they need not be seen as determining our action, nor must our action conform exactly to the form of rule, albeit the rule influences the action, by guiding our choice.

Rules do have a form. In fact, Lawson (2003: 36) suggests that social rules are generalised procedures of action which "can be expressed as injunctions of the 
form 'if $\mathrm{x}$ do $\mathrm{y}$ under conditions $\mathrm{z}$ "'. But so does marble, which from a physical or chemical perspective can be seen as being characterised by a given atomic or molecular form or structure, and belonging to a given geological type or form. But in what concerns the efficient cause which is a particular action of the sculptor, marble is taken as an (emergent) material cause, just like in what concerns the efficient cause which is a particular human agent, social rules are taken as an (emergent) material cause.

\section{THE HUMAN AGENT AS A STRUCTURED INDIVIDUAL}

Searle evades the problems associated with the conceptualisation of the putative causal role of social structures, using the term causation to denote only physical causation. Manicas (2006: 57) writes that "Searle has rightly argued that more fundamental than the distinction between 'nature' and 'culture', or 'mind' and 'body' is the distinction between those features of the world that exist independently of us and those that are dependent on us for their existence". Searle (1995) names the features of the world that exist independently of us as "brute facts", and the features of the world that are dependent on us for their existence as "institutional facts". Now, if Searle wants to give priority to brute (or physical) causation, how can he accommodate social institutions in his framework?

Searle conceptualises the causal impact of social institutions of human behaviour through his thesis of the Background. Searle argues that: "[i]ntentional states function only given a set of Background capacities that do not themselves consist in intentional phenomena" (Searle 1995: 129). For Searle, the Background is "the set of nonintentional or preintentional capacities that enable intentional states to function" (Searle 1995: 129). Capacities are "abilities, dispositions, tendencies, and causal structures generally" (Searle 1995: 129, emphasis in original).

The Background is thus a key element to conceptualise neurophysiological causation and the impact of social institutions on the latter. Searle (1995: 129) argues that since "we do not know how these structures function at a neurophysiological level, we are forced to describe them at a much higher level". Searle explains that the term "[e]nabling is meant, then, to be a causal notion" (Searle 1995: 130), that is, these pre-intentional or non-intentional capacities "function causally in the production of certain sorts of intentional phenomena" (Searle 1995: 130), where intentional states are "conscious". Searle continues:

\footnotetext{
"The key to understanding the causal relations between the structure of the Background and the structure of social institutions is to see that the Background can be causally sensitive to the specific forms of the constitutive rules of the institutions without actually containing any beliefs or desires or representations of those rules" (Searle 1995: 141).
}

The Background's capacities and causal structures include our dispositions and tendencies to engage in given intentional states, including habits and dispositions 
to engage in social behaviour. It is important to note that, for Searle, the Background enables rule following behaviour, but some actions enabled by the Background need not conform to any rule at all.

By using the thesis of the Background in order to accommodate the causal effects of social institutions, Searle ends up not clarifying the ontological status of social structures. For if Background causation takes place at the physical level of brute causation, one can, using Searle's framework, conceptualise the putative causal role of social institutions resorting only to brute causation. In earlier writings, Sen addresses a similar problem, and argues:

\footnotetext{
"There is thus a certain difference between the form of physical laws and that of social laws (...). The difference is, however, not necessarily due to any fundamental dissimilarity between physical and human causal relations (the human relations may ultimately be purely biochemical), but due to the number of variables involved in any function" (Sen 1959: 105).
}

Of course, Sen does not necessarily embrace any type of physical reductionism here, since he only suggests that human relations may ultimately bio-chemical, not that we are sure they are. Sen seems to imply here that we are only sure of the existence of causal relations in the social realm, not of the level of reality where causality is placed.

Sen does not clarify whether the higher "number of variables involved" leads to emergent properties in the social realm. But this would be the central question to address here, together with the connected question of whether the social reality that emerges can be seen as having a causal role of its own (including a causal role on the lower level from which it emerged), or whether causality exists only at lower level, such as the bio-chemical level, or in the non-conscious capacities and dispositions that Searle refers to in his thesis of the Background.

It could be argued, for example, that to ascribe causality to physical phenomena only has the advantage of avoiding the reification of social structures which, Harré and Varela (1996) argue, would follow from the ascription of causal efficacy to social structures. However, the argument made above, that human agency is the efficient cause, while social structures are the material cause, of an action, allows us to avoid the reification of social structures without reducing causality to the physical (or bio-chemical) realm.

But one must remember that to acknowledge social structures as material causes is not to deny that social structures, like any emergent entity, are permanently dependent upon the lower level from which they emerged, such as the nonconscious capacities and dispositions which enable social behaviour. In fact, such capacities and dispositions are essential for the critical realist explanation of social structures as emergent entities.

For example, Lawson (2003) refers to ideas very similar to Searle's thesis of the Background, although using a different term for it, namely the term "habitus", following Pierre Bourdieu (1990), but this does not prevent Lawson from reaching 
a conception of social reality where the latter is emergent from the level of physical causation - for a comparison of Lawson's and Searle's conceptions see Faulkner (2002).

A notion similar to Bourdieu's "habitus", or Searle's Background, may in fact be crucial to Sen's conception of agency too. Sen $(1987,1997,2002)$ argues that mainstream economic theory, and rational choice theory, should recognise that human agents have multiple motivations, and that one preference ordering is not sufficient to explain behaviour, for conflicting human motivations may lead to the existence of multiple preference orderings, and even incomplete preference orderings, due to unresolved conflicts.

But Sen's assumption of multiple motivations presupposes a conception of a structured individual, which is best accommodated by acknowledging the coexistence of multiple dispositions in the human individual, such as Bourdieu (1990) does in his notion of the "habitus", or Searle does in his theory of the Background - for an analysis of the implications of Searle's thesis of the Background for mainstream economic theory, and the rational choice theory approach that Sen (2002) also criticises, see also Runde (2002).

In fact, the role of underlying capacities and dispositions in human behaviour is much related to the Aristotelian notion of potential, which is often recognised to be one of the key ontological concepts in Sen's work, especially in his capability approach, where capabilities are seen as potential functionings-see Martins (2006) for a discussion.

Now, it is sometimes held that one of the main dissonances between the Aristotelian view - which Sen (1999: 289) recognises as one of his main influences - and the Platonic view of human behaviour is that, contrarily to Plato, Aristotle held that virtue consists in the practical habit of moderating affections, rather than in moderate and right affections themselves - for a discussion see Adam Smith (2002[1759]: 315-321). So if virtuous behaviour lies in the habit of moderation (rather than on moderate behaviour itself), as Aristotle believed, a stronger emphasis should be placed on the ontological preconditions that enable virtuous habits to emerge (rather than emphasising virtuous behaviour regardless of its conditions of possibility).

The different types of rules Sen (1997) mentions, viz. "conventional rule following", "social commitment", or "moral imperatives" can involve different levels of conscious reflexivity. Reasoned scrutiny of goals and values, an essential aspect of human agency in Sen's perspective, will certainly be also a central feature of social behaviour. But note that even this type of rational activity is possible only because of the "habitus", or the Background's capacities and dispositions which enable intentional states.

Hence, ontological analysis of underlying capacities and dispositions is essential to help us to understand: (i) the habits of moderating affections and moral sentiments that Aristotle, Adam Smith and Sen refer to; (ii) how rules can be continuously reproduced in our daily lives even though reasoned scrutiny of goals 
and values is not permanently undertaken, enabling behaviour to be done according to a sense of collective identity; and (iii) reasoned scrutiny of goals and values. An understanding of these ontological conditions of possibility of social rules of conduct and behaviour is essential for the development of Sen's critique of mainstream economic theory. The causal role of these capacities and dispositions is very important for critical realism, Searle and Sen.

\section{CONCLUDING REMARKS}

Human agents follow social rules of behaviour that are often out of phase with their individual goals. Sen's argument is not that self-interest must include altruistic concerns, for in Sen's definition self-goals may already include these concerns. Sen's point is that even when self-goals include altruist concerns, cooperation cannot be explained as the outcome of behaviour driven by those goals only. This view contrasts with the line of argument of traditional game theory analysis, where social behaviour is explained as the outcome of the strategic interaction of human agents who engage in optimising behaviour (driven by self-goal pursuit).

The transformational model of social activity renders Sen's suggestion that "fixed rules" are often "taken for granted" compatible with Sen's view of agency, rationality and freedom. Sen's claim that one must "take for granted the case for certain patterns of behaviour toward others", while "acting according to fixed rules", does certainly point towards the rejection of voluntarism, and of explanations of social rules where these are entirely derived from (or explained only in terms of) the individual interplay of self-goal seeking agents. So social structures cannot be explained only in terms of the individual interaction of self-goal pursuing agents.

However, if one wants to adopt Sen's viewpoint, one can neither argue that social structures determine human agency, nor that they are reified in any sense, for Sen argues that freedom of choice and reasoned scrutiny of goals and values are essential features of human behaviour - see, for example, Sen (2002, 2006). The type of social behaviour Sen refers to can be best understood within the transformational conception of social activity: cooperation can exist because agents draw upon an ontologically distinct social structure that they continuously reproduce and/or transform. This ontologically distinct social structure is a material cause which, combined with the efficient causation of the human agent, leads to human action.

Furthermore, one can say that in Sen's perspective, human beings are able to "identify" with a community, and to pursue collective values, because they share beliefs, desires and intentions - that is, because of what Searle calls collective intentionality. Notions like collective intentionality and Background capacities (or Bourdieu's "habitus") can provide further help in the task of understanding social behaviour. 
Of course, one must bear in mind that the work of Sen, Searle or critical realists provides only the conceptual tools for a different theory, by clarifying the meaning of the underlying categories that are used in social theories. This clarification of concepts and categories plays a distinct role from that of providing a fully-fledged theory of social behaviour. It is just the starting point for a different theory of social behaviour.

\author{
Nuno Martins \\ Portuguese Catholic University \\ Faculty of Economics and Management \\ Rua Diogo Botelho, 1327 \\ 4169-005 Porto, Portugal \\ nmartins@porto.ucp.pt
}

Acknowledgments. For most helpful comments on an earlier draft I am most thankful to Tony Lawson, Stephen Pratten, Jochen Runde, and the participants of the Collective Intentionality VI Conference, at the University of California, Berkeley. I also benefited much from the comments of three anonymous referees on a more recent draft. The usual disclaimer applies. I gratefully acknowledge financial support from the Portuguese Government, given through the Portuguese Foundation for Science and Technology (FCT).

\title{
NOTES
}

${ }^{1}$ Sen explains that "economics has had two rather different origins, but related in rather different ways, concerned respectively with 'ethics' on the one hand, and what may be called 'engineering' on the other." (Sen 1987: 2/3). Sen then argues that a closer contact with the "ethics-related tradition" which "goes back at least to Aristotle" (1987: 3) can enrich economic theorising. In addressing this relation between ethics and economics, Sen points to two main areas of contact: the "ethics-related view of motivation"; and the "ethics-related view of social achievement". The "ethics-related view of motivation" is concerned with the relation between ethics and behaviour, while the "ethics-related view of social achievement" addresses the issue of how one should judge social achievement, or in Aristotle's terms, "the good of man" (as discussed in Aristotle's Politics, and in The Nichomachean Ethics). Sen refers to the "ethics-related view of motivation" as the "Socratic" question of "how should one live" (Sen 1987: 10), while referring to the "ethics-related view of social achievement" as the "Aristotelian" question (Sen 1987: 9/10). Much of Sen's contribution has been concerned with developing these two views of ethics. Sen's writings on rational behaviour, choice and agency have a strong influence of the "ethics-related view of motivation" (the "Socratic" question). Sen draws upon the moral philosophy of authors such as Adam Smith, explaining how many moral motivations that are developed by these authors cannot be accommodated by mainstream microeconomic theorising. Sen's work on welfare economics and his "capability approach", on the other hand, has 
been much concerned with the "ethics-related view of social achievement" (the "Aristotelian" question), and with the assessment of human advantage and well-being. Of course, the "ethics-related view of motivation" and the "ethics-related view of social achievement", are closely related, and Sen has also argued that questions of social achievement must be taken into account in human motivation. In this sense, the "ethics-related view of motivation" is not an exclusively "Socratic" question. Rather, it has much to do with the "Aristotelian" question as well.

${ }^{2}$ When all players do not cooperate, we have the Nash (1951) equilibrium of a single simultaneous move game. A Nash equilibrium is defined as one in which all players play the best response to the other player's strategy - and in the simultaneous move prisoner's dilemma game the best response strategy is the non-cooperative strategy, for all players. In an infinitely repeated game situation, the cooperative outcome could be achieved if both players would have the following strategy: to cooperate first, and afterwards to cooperate if and only if the other player has cooperated in the previous stage. This way of acting in the context of an infinitely repeated game is usually called a Nash reversion strategy: players behave cooperatively if the other players also do so, but when they observe that the other players are not behaving cooperatively, they revert to the non-cooperative strategy (that constitutes the Nash equilibrium of a single simultaneous move game). In a finitely repeated game, however, it becomes more difficult to explain cooperative behaviour. In a finitely repeated game, players will choose the non-cooperative strategy at the last stage of the game, for at the last stage of the game they will be in the same situation as in a single simultaneous move game (where not cooperating is the dominant strategy). And then, by backward induction (that is, by successively moving to the previous stage of the game until the first stage is reached) one can see that the non-cooperative strategy will be played at every stage of the game, because in all the successive stages of the game the players will be in a situation similar to that of a single simultaneous move game. So it is always preferable for players not to cooperate in the finitely repeated prisoner's dilemma game. In the finitely repeated prisoner's dilemma game, the possibility of cooperation is often explained by relaxing assumptions on the mutual knowledge of the players, or by assuming myopic behaviour. Amartya Sen argues that "[i]n the formal literature, there have been various attempts to explain the emergence of cooperation by introducing some kind of a 'defect' in either the knowledge, or the reasoning of the players" (Sen 1987: 84), and hence each player cooperates because (s)he does not realize that the non-cooperative strategy would bring her or him a higher individual payoff.

${ }^{3}$ In a game represented in extensive form, beliefs are modelled through the probabilities that the players attach to the event of being at a given information set. The solution concept of a "weak perfect Bayesian equilibrium", for example, draws upon the existence of such a system of beliefs (in order to explain how equilibrium occurs). This weak perfect Bayesian equilibrium consists in a profile of strategies and a system of beliefs, where the profile of strategies is sequentially rational (i.e., the player has no incentive at any stage to change strategies given her or his beliefs) and the system of beliefs is derived using the Bayes' rule (whenever possible) at each information node. A Nash equilibrium given a system of beliefs is defined similarly, with the difference that in such a case sequential rationality is required only in the equilibrium path. These beliefs are about what happened until the present stage. In game theory the system of beliefs reflects information on what other players may do insofar as it assigns probabilities to the event of being at a given information set given past actions. Notice that the relation between what Searle refers to as beliefs, and what is usually referred to as a "system of beliefs" in game theory, would require further elaboration. But the fundamental aspect in both conceptions of beliefs, for our present purposes, is an assignment of a probability to other agents' actions given past information. 


\section{REFERENGES}

Archer, M. 1995. Realist Social Theory: The Morphogenetic Approach, Cambridge University Press, Cambridge.

Archer, M. 2000. Being Human: The Problem of Agency, Cambridge University Press, Cambridge.

Archer, M. 2007. The Ontological Status of Subjectivity: The Missing Link Between Structure and Agency, in Lawson, C., J. Latsis and N. Martins (Eds.), Contributions to Social Ontology, London, Routledge.

Archer, M., R. Bhaskar, A. Collier, T. Lawson and A. Norrie (Eds.), 1998. Critical Realism: Essential Readings, Routledge, London.

Bhaskar, R.A. 1975. A Realist Theory of Science, London, Verso.

Bhaskar, R.A. 1989. The Possibility of Naturalism, Brighton (UK), Harvester.

Bourdieu, P. 1990. The Logic of Practice, Cambridge, Polity.

Elder-Vass, D. 2007. For Emergence: Refining Archer's Account of Social Structure. Fournal for the Theory of Social Behaviour, 37, 25-44.

Faulkner, P. 2002. Some Problems with the Conception of the Human Subject in Critical Realism, Cambridge Fournal of Economics, 26, 739-751.

Harré, R., and Bhaskar, R. 2001. How to Change Reality: Story v. Structure-A Debate. In J. López and G. Potter (Eds.), After Postmodernism: An Introduction to Critical Realism (pp. 22-39). London: Athlone Press.

Hollis, M., and Sugden, R. 1993. "Rationality in Action", Mind, 102, 1-35.

Kaidesoja, T. 2007. Exploring the Concept of Causal Power in a Critical Realist Tradition. Fournal for the Theory of Social Behaviour, 37, 63-87.

KIng, A. 2007. Why I am not An Individualist, fournal for the Theory of Social Behaviour, 37, 211-219.

Kreps, D., and R. WiLson 1982. Sequential Equilibria, Econometrica, 50, 863-94.

Lawson, T. 1997. Economics and Reality, London, Routledge.

Lawson, T. 2003. Reorienting Economics, London, Routledge.

Lewis, P.A. 2000. Realism, Causation and the Problem of Social Structure, fournal for the Theory of Social Behaviour, 30, 249-268.

Manicas, P. 2006. A Realist Philosophy of Social Science: Explanation and Understanding. Cambridge, Cambridge University Press.

Martins, N. 2006. Capabilities as Causal Powers, Cambridge Fournal of Economics, 30, 671 685.

Martins, N. 2007a. Ethics, Ontology and Capabilities, Review of Political Economy, 19, 3753.

Martins, N. 2007b. Realism, Universalism and Capabilities, Review of Social Economy, 65, 253-278.

Nash, J.F. 1951. Non-Cooperative Games, The Annals of Mathematics, 2nd Ser., 54, 286295.

PArfit, D. 1981. Prudence, Morality and the Prisoner's Dilemma, Proceedings of the British Academy for 1979, London, Oxford University Press.

Parfit, D. 1984. Reasons and Persons, Oxford, Clarendon Press.

Porpora, D. 2007. On Elder-Vass: Refining a Refinement. Fournal for the Theory of Social Behaviour, 37, 195-200.

Putnam, H. 2002. The Collapse of the Fact/Value Dichotomy and Other Essays, Cambridge (MA) and London, Harvard University Press.

Runde, J. 2002. Filling in the Background, Fournal of Economic Methodology, 9, 11-30.

Searle, J.R. 1995. The Construction of Social Reality, London: Penguin.

SEN, A. 1959. Determinism and Historical Predictions, Enquiry, 2, 99-115.

SEn, A. 1987. On Ethics and Economics, Oxford and New York, Basil Blackwell. 
Sen, A. 1997. Maximization and The Act of Choice, Econometrica, 65, 745-779.

Sen, A. 1999. Development as Freedom, Oxford, Oxford University Press.

Sen, A. 2002. Rationality and Freedom, Cambridge Massachussets: The Belknap Press of Harvard University Press.

Sen, A. 2006. Identity and Violence: The Illusion of Destiny (Issues of Our Time), New York and London, W.W. Norton and Company, Ltd.

Smith, A. 2002 [1759]. The Theory of Moral Sentiments, Cambridge, Cambridge University Press.

Sugden, R. 2000. "Team Preferences", Economics and Philosophy, 16, 175-204.

Varela, C. 2007. Elder-Vass's Move and Giddens's Call. Fournal for the Theory of Social Behaviour, 37, 201-210.

Varela, G.R., and Harre, R. 1996. Conflicting Varieties of Realism. Fournal for the Theory of Social Behaviour, 26, 313-325.

Walsh, V. 2000. Smith after Sen, Review of Political Economy, 12, 5-25.

Walsh, V. 2003. Sen after Putnam, Review of Political Economy, 15, 315-394. 